\title{
BMJ Open Quality Spread of quality improvement in healthcare across South Asian subcontinent
}

Vikram Datta (1) , ${ }^{1,2}$ Nigel Livesley ${ }^{3}$

To cite: Datta V, Livesley N. Spread of quality improvement in healthcare across South Asian subcontinent. BMJ Open Quality 2021;10:e001600. doi:10.1136/ bmjoq-2021-001600

Accepted 6 July 2021
Check for updates

(C) Author(s) (or their employer(s)) 2021. Re-use permitted under CC BY-NC. No commercial re-use. See rights and permissions. Published by BMJ.

${ }^{1}$ Neonatology, Kalawati Saran Children's Hospital, New Delhi, Delhi, India

${ }^{2}$ Neonatology, Lady Hardinge Medical College, New Delhi, Delhi, India

${ }^{3}$ Independent Healthcare Consultant, Fremont, California, USA

Correspondence to Professor Vikram Datta; drvikramdatta@gmail.com
Poor quality of care is a significant bottleneck in our quest to achieve universal healthcare as envisaged in Sustainable Development Goal 3.8. ${ }^{1}$ Globally, nearly 5 million lives are lost annually due to suboptimal quality of care. Poor quality now contributes to more deaths than lack of access to care. Health providers in low-income and middle-income countries (LMICs) often perform less than half of recommended evidence-based care actions as has been detailed in the recent report of the Lancet Global Health Commission. ${ }^{2}$ A significant 'know-do gap' exists concerning how clinical teams deliver care compared with the existing evidence. This gap is explained by the interplay of complex human and psychosocial factors which influence service delivery at the point of care. More frequently, efforts to improve quality of care focus on building an individual's knowledge and skills (eg, training and supervision) without addressing complex teamwork, organisational and structural issues. In contrast, quality improvement (QI) methods use approaches that health workers can adopt to address such barriers using a common-sense approach. Batalden aptly defines QI as a combined and unceasing effort of everyone-healthcare professionals, patients and their families, researchers, payers, planners and educators-to make the changes that will lead to better patient outcomes (health), better system performance (care) and better professional development. $^{3}$

Introducing the concept of QI into the health systems of low-income and middleincome economies is a challenging task. The journey of the QI movement in South Asia has been fascinating with its fair share of twists and turns. In 2016, the Indian government, key development partners WHO South East Asia Regional Office (SEARO), United States Agency for International Development and other United Nations agencies hosted and introduced a selected group of healthcare professionals from 11 member nations in the
SEARO region to a simplified method of QI. ${ }^{4}$ This session led to create a simple point-ofcare QI (POCQI) method. POCQI has been subsequently widely used in field settings across SEARO member nations with the support of national networks such as Nationwide Quality of Care Network (NQOCN), India. ${ }^{5}$ It has led to member nations adopting and implanting QI in their health systems, often starting with the point-of-care interventions. Over the last 5 years across South Asia, the scale up of QI interventions and their hardwiring in the health systems has been heterogeneous.

The current special edition for South Asia is an attempt to collect, collate and highlight improvement stories of teams working in challenging settings across South Asia. A quick survey of the published literature on the use of QI methods across various clinical domains reveals a significant lack of representation from the LMIC settings. Does it mean that improvement stories only exist in the developed world? Do they not exist in the LMIC settings where QI is of potential importance to ensure a safe, affordable, efficient and equitable health system operating amidst severe resource constraints? An analysis conducted by the journal's editorial board concluded that there are two major bottlenecks to the conduction and publication of QI stories from LMIC settings. First, implementing and sustaining a QI project requires a set of facilitatory factors, namely opportunities, that is, an enabling environment, ability or skills in the team, motivation and access to requisite resources. ${ }^{6}$ Second, documenting the improvement story requires significant mentoring and financial support. Both of the above-mentioned factors are found wanting in varying degrees in facilities across LMIC settings. NQOCN and BMJ Publishing Group agreed to publish an annual South Asia edition of the BMJ Open Quality Journal to offset these bottlenecks. This initiative, for the year 2020-21, has been possible mainly due to a 
generous grant from UNICEF India. Three writers' workshops followed up the call for papers to mentor prospective authors to the submission guidelines and the writing style of the journal. The writers' workshops were followed by one-to-one mentoring of the prospective authors.

The issue received 54 submissions and will make interesting reading. Among the articles worth mentioning here is an article by Parmar et $a l^{7}$ on rationalising oxygen usage across the special newborn care units. It documents how common-sense QI approaches can save precious resources and prevent harm to the admitted neonates. Batthula $e t a l^{8}$ discuss how innovative educational interventions paired with monitoring and evaluations can reduce hospital-acquired infections in their paper on reducing late-onset sepsis in very low birthweight neonates with central lines. In their paper on establishing the practice of birth companion in a tertiary care centre, Bharti et a $\hat{\theta}^{\hat{P}}$ have tried to sensitise the reader to the vital elements of respectful maternity care, which forms a part of ongoing national and international advocacy efforts.

NQOCN, India with the support of Key Development Partners, has documented its journey to develop an implementation framework for QI in India in a paper entitled: 'Development of a Framework of Intervention Strategies for Point of Care Quality Improvement at Different levels of the Healthcare Delivery System in India: Initial Lessons'. This paper can serve as a guidance document for teams in other LMICs planning to scale up QI across their health systems. In the paper on advancing emergency airway management by reducing rapid sequence intubation time, Gopinath et $a l^{10}$ have addressed this issue using simple QI tools. The issue also showcases innovative out of the box use of QI tools, as has been demonstrated by Bhartia $e t a l^{11}$ in their article describing how they reduced traffic congestion in the emergency driveway of a private hospital. Besides these, the issue aptly covers topics related to the use of QI to address COVID-19related quality of care concerns.

We are certain the issue will serve as a key resource to share the learnings from the region with the larger global audience. We hope the special edition would encourage teams in South Asia to carry out QI initiatives at scale with longer sustenance phases with the active involvement of the health system.We look forward to the 2022 South Asia Special Edition and a greater participation from the teams across the region.

Acknowledgements We thank the BMJ Open Quality South Asia Edition Editorial Board of Dr Sushil Srivastava, Dr Naveen Jain, Dr Amit Gupta, Dr Vishwas Chhapola, Dr Ajit Sudke and Dr Ashok Kumar for their kind support and Dr Sonam Jain for coordination of the peer-review process. A special issue of this magnitude within strict timelines and an ongoing pandemic would not have been possible without the full support of over 100 peer reviewers who, despite their busy schedules, took time out to review the submitted manuscripts critically. We thank Dr Kieran Walsh from BMJ for conducting mentoring sessions for prospective authors, Janet 0 Flaherty, publisher, BMJ Publishing; Helen Crisp, editor-in-chief, BMJ Open Quality and Mr Prashant Mishra, BMJ India, for facilitating this special edition.

Contributors Both authors are responsible for the conceptualisation and drafting of the editorial and have reviewed and approved the manuscript.

Funding This issue was funded by UNICEF India. Publication of this article is made open access with funding from the Nationwide Quality of Care Network.

Competing interests None declared.

Patient and public involvement Patients and/or the public were not involved in the design, or conduct, or reporting, or dissemination plans of this research.

Patient consent for publication Not required.

Provenance and peer review Not commissioned; internally peer reviewed.

Open access This is an open access article distributed in accordance with the Creative Commons Attribution Non Commercial (CC BY-NC 4.0) license, which permits others to distribute, remix, adapt, build upon this work non-commercially, and license their derivative works on different terms, provided the original work is properly cited, appropriate credit is given, any changes made indicated, and the use is non-commercial. See: http://creativecommons.org/licenses/by-nc/4.0/.

ORCID iD

Vikram Datta http://orcid.org/0000-0002-1047-6884

\section{REFERENCES}

1 Kruk ME, Gage AD, Arsenault C, et al. High-Quality health systems in the sustainable development goals era: time for a revolution. Lancet Glob Health 2018;6:e1196-252.

2 Rowe AK, Rowe SY, Peters DH, et al. Effectiveness of strategies to improve health-care provider practices in low-income and middle-income countries: a systematic review. Lancet Glob Health 2018;6:e1163-75.

3 Batalden PB, Davidoff F. What is "quality improvement" and how can it transform healthcare? Qual Saf Health Care 2007;16:2-3.

4 World Health Organization, Regional Office for South-East Asia. A regional framework for improving the quality of care for reproductive, maternal, neonatal, child and adolescent health in south-east Asia region, 2015. Available: https://apps.who.int/iris/rest/bitstreams/ 1174069/retrieve [Accessed 27 Jun 2021].

5 Datta V, Srivastava S, Singh M. Formation of quality of care network in India: challenges and way forward. Indian Pediatr 2018;55:824-7.

6 Semrau KEA, Hirschhorn LR, Marx Delaney M, et al. Outcomes of a coaching-based who safe childbirth checklist program in India. $N$ Engl J Med 2017;377:2313-24.

7 Parmar J, Pawar V, Warathe A, et al. Rationalising oxygen usage in a level II special newborn care unit in Madhya Pradesh, India. BMJ Open Qual 2021.

8 Batthula V, Somnath SH, Datta V. Reducing late-onset neonatal sepsis in very low birthweight neonates with central lines in a lowand-middleincome country setting. BMJ Open Qual 2021.

9 Bharti J, Kumari A, Zangmo R, et al. Establishing the practice of birth companion in labour ward of a tertiary care centre in India- a quality improvement initiative. BMJ Open Qual 2021.

10 Gopinath B, Sachdeva S, Kumar A, et al. Advancing emergency airway management by reducing intubation time at a high-volume academic emergency department. BMJ Open Qual 2021.

11 Bhartia S, Wahi P, Sharma A. Reducing congestion in the emergency driveway of a small hospital in New Delhi, India. BMJ Open Qual 2021. 